\title{
PROPOSTA DE EDUCAÇÃO AMBIENTAL COMO INSTRUMENTO DE APOIO À IMPLANTAÇÃO E MANUTENÇÃO DE UM POSTO DE ORIENTAÇÃO E RECEBIMENTO DE RECICLÁVEIS SECOS EM UMA ESCOLA ESTADUAL DE ENSINO FUNDAMENTAL
}

Paulo Henrique Peira Ruffino

\begin{abstract}
Dissertação apresentada à Escola de Engenharia de São Carlos da Universidade de São Paulo, como parte dos requisitos para obtenção do título de Mestre em Hidráulica e Saneamento.
\end{abstract}

ORIENTADOR: Prof. DR. VALDIR SCHALCH

SÃo CARLOS

2001 
Ao meu Pai Prof. Dr. Rosalvo Tiago Ruffino que, como tantos outros professores, contribuiu de maneira significativa na consolidação da Escola de Engenharia de São Carlos na qual hoje tenho a honra de participar enquanto pós-graduando. 


\section{AGRADECIMENTOS}

A Deus por mais esta oportunidade de vida.

Ao amigo e orientador Prof. Dr. Valdir Schalch pela liberdade e interesse na linha de pesquisa desenvolvida.

Ao amigo Dr. Ednílson Viana pelo apoio e motivação junto ao desenvolvimento do trabalho, sem os quais não seria possível concluir os objetivos propostos.

Às amigas Sá e Pavi pela consideração e apoio durante a caminhada.

À toda equipe da Escola Estadual Prof. Bento da Silva César.

À minha esposa Sandra e minha filha Giulia que possibilitaram a segurança e a disposição necessárias para tal empenho.

À Sílvia representando o Setor de Biologia e Educação Ambiental CDCC/USP pelo espaço cedido ao longo destes últimos anos e, principalmente pelas calorosas discussões em nome da Educação Ambiental.

À Luz, Rumy, Rita e "toda" a equipe de trabalho em EA que conseguimos agregar nestes anos de trabalho.

A todos que contribuíram nas reformulações tão necessárias à vida contemporânea.... 